\title{
ph Foliar e Deposição de Gotas de Pulverização em Plantas DANINHAS AQUÁTICAS: Brachiaria mutica, Brachiaria subquadripara E Panicum repens ${ }^{1}$
}

\author{
Leaf pH and Spray Droplet Deposition in Aquatic Weeds: Brachiaria mutica, Brachiaria \\ subquadripara and Panicum repens
}

COSTA, N.V. ${ }^{2}$, MARTINS, D. ${ }^{3}$, RODELLA, R.A ${ }^{3}$ e COSTA, L.D.N.C. ${ }^{4}$

\begin{abstract}
RESUMO - A diversidade morfológica da superfície foliar existente entre as espécies de plantas e a presença de estruturas foliares, como tricomas, estômatos, cutícula e ceras, podem exercer grande influência na aderência e deposição das gotas de pulverização, assim como na absorção do herbicida. Dessa forma, o objetivo do presente trabalho foi estudar, em plantas daninhas aquáticas emersas (Brachiaria mutica, Brachiaria subquadripara e Panicum repens), o pH foliar, bem como a área de molhamento de gotas de pulverização na superficie foliar adaxial e abaxial. O experimento foi conduzido no Núcleo de Pesquisas Avançadas em Matologia - NUPAM, pertencente à Faculdade de Ciências Agronômicas de Botucatu/SP - UNESP. As plantas foram cultivadas em caixas d'água no campo, quando elas atingiram seu pleno desenvolvimento (antes do florescimento), foram feitas as avaliações de $\mathrm{pH}$ foliar e da área de molhamento de gotas de pulverização. As tensões superficiais das gotas depositadas $(0,5 \mu \mathrm{L})$, apresentadas pelas soluções de glyphosate aplicado isoladamente $\left(5,0 \% \mathrm{v} \mathrm{v}^{-1}\right.$, Rodeo $480 \mathrm{~g} \mathrm{~L}^{-1}$ e.a. - produto comercial), glyphosate + Aterbane BR $(5,0 \%+$ $\left.0,5 \% \mathrm{v} \mathrm{v}^{-1}\right)$, glyphosate + Silwet L-77 $\left(5,0 \%+0,05 \% \mathrm{v} \mathrm{v} \mathrm{v}^{-1}\right)$, além das soluções com os adjuvantes isolados, Aterbane BR $\left(0,5 \% \mathrm{v} \mathrm{v} \mathrm{v}^{-1}\right)$ e Silwet L-77 $\left(0,05 \% \mathrm{v} \mathrm{v}^{-1}\right)$, foram respectivamente de 72,1 ; 28,$7 ; 23,3 ; 37,3$; e $22,1 \mathrm{mN} \mathrm{m}^{-1}$. As médias obtidas de $\mathrm{pH}$ foliar variaram entre 5,71 e 6,03 , destacando-se a espécie B. mutica, com valores de 5,72 e 6,03 para as faces adaxial e abaxial, respectivamente. Contudo, mais estudos devem ser realizados para verificar a influência do $\mathrm{pH}$ foliar na absorção de herbicidas por espécies daninhas aquáticas. Das plantas daninhas aquáticas avaliadas, $B$. subquadripara foi a espécie que obteve as maiores médias de área de molhamento nas faces adaxial e abaxial da folha, proporcionadas pelas soluções de glyphosate + Aterbane BR, glyphosate + Silwet L-77 e Silwet L-77, com valores de $6,44-4,36 ; 7,77-10,59$; e $10,94-10,28 \mathrm{~mm}^{2}$, respectivamente.
\end{abstract}

Palavras-chave: plantas aquáticas, glyphosate, $\mathrm{pH}$ foliar, adjuvantes e molhamento.

ABSTRACT - The aim of this research was to study leaf $p H$ and to evaluate the spreading area after application of solution surfactants on the following aquatic weeds: Brachiaria mutica, Brachiaria subquadripara and Panicum repens. Aquatic weeds were cultivated in reservoirs containing water under field conditions with foliar tissues collected when plants reached their full development (before flowering). Leaf $p H$ medium values varied between 5.71 and 6.03, with B. mutica standing out with the highest $p H$ values $(5.72$ and 6.03 for the upper and lower surfaces, respectively). Surface tension of droplets for glyphosate alone $\left(5.0 \% v v^{-1}\right)$, glyphosate + Aterbane BR $\left(5.0 \%+0.5 \% v v^{-1}\right)$, glyphosate + silwett L-77 $\left(5.0 \%+0.05 \% v v^{-1}\right)$, and surfactants alone, Aterbane BR $\left(0.5 \% v v^{-1}\right)$ and Silwet $L-77\left(0.05 \% v v^{-1}\right)$ was, respectively, 72.1; 28.7; 23.3; 37.3 and $22.1 \mathrm{mN} \mathrm{m}^{-1}$. B. subquadripara obtained the highest spreading area for the upper and lower leaf surfaces.

Key words: aquatic weeds, glyphosate, leaf $\mathrm{pH}$, surfactants and spreading.

Recebido para publicação em 23.6.2004 e na forma revisada em 21.4.2005.

2 Eng.-Agr., aluno de Pós-Graduação, Dep. de Produção Vegetal-Agricultura, FCA/UNESP, Caixa Postal 237, $18603-970$ BotucatuSP, <neumarcio@fca.unesp.br>; ${ }^{3}$ Prof. Dr., Dep. de Produção Vegetal-Agricultura, FCA/UNESP; ${ }^{4}$ Aluna de graduação FCA/UNESP. 


\section{INTRODUÇÃO}

Nos ecossistemas aquáticos, as plantas aquáticas são a principal fonte produtora de biomassa (Esteves, 1998). O desenvolvimento excessivo dessas plantas pode ocasionar vários inconvenientes com relação ao transporte hidroviário, à pesca, à produção de energia, ao abastecimento de água, aos esportes náuticos, à proliferação de vetores de doenças, entre outros. Do ponto de vista ambiental, algumas espécies de crescimento rápido podem suprimir outras menos agressivas, desejáveis para manutenção da diversidade, ou modificar negativamente algumas características físicas da água (Martins et al., 1999; Cardoso et al., 2002).

Em levantamento realizado nos seis reservatórios operados pela Companhia Energética de São Paulo-CESP (Três Irmãos, Jupiá, Ilha Solteira, Porto Primavera, Paraibuna e Jaguari), foram identificadas 29 espécies de plantas aquáticas, distribuídas em 17 famílias; dentre as espécies mais freqüentes nos reservatórios, destacam-se Brachiaria subquadripara, Brachiaria mutica, Eichhornia crassipes, Typha spp. e Salvinia molesta, além das espécies submersas Egeria densa, Egeria najas e Ceratophyllum demersum (Tanaka et al., 2002). Espécies aquáticas emersas, como Brachiaria mutica, Brachiaria subquadripara e Panicum repens, já estão se tornando problemáticas em reservatórios hidrelétricos e em outros tipos de reservatório, devido à sua grande capacidade de reprodução e produção de biomassa.

O método de manejo mais difundido e que melhor tem conciliado a eficiência e o custo de controle de plantas daninhas aquáticas nos EUA é a utilização dos herbicidas 2,4-D, glyphosate e diquat, que são registrados para o uso em ambientes aquáticos (Cardoso, 2000; Antuniassi et al., 2002; Cardoso et al., 2003). $\mathrm{O}$ controle químico pode se apresentar altamente seletivo às plantas daninhas aquáticas, além de evitar danos à fauna aquática, através da coleta indesejada de insetos e alevinos, como ocorre no controle mecânico. Dentre os herbicidas existentes, o glyphosate destacase por possuir elevada eficiência no controle de plantas daninhas emergentes e flutuantes; é um herbicida sistêmico, de ação total (não-seletivo), que atua sobre a inibição da atividade enzimática responsável pela formação dos aminoácidos aromáticos essenciais (triptofano, tirosina e fenilalanina), os quais são precursores de outros produtos, como lignina, alcalóides, flavonóides e ácidos benzóicos (Rodrigues \& Almeida, 1998; Amarante Jr. et al., 2002).

A eficácia do controle químico está relacionada a diversos fatores, dentre os quais as características da planta destacam-se como variável importante, sendo atualmente pouco estudada. A morfologia externa da superficie foliar das plantas é altamente variável, sendo caracterizada pela presença de um revestimento de proteção, a epiderme e a cutícula, podendo haver também ceras epicuticulares e tricomas. Hess \& Falk (1990) afirmam que a topografia da superficie foliar e a presença de ceras e tricomas podem influenciar a distribuição de um determinado herbicida aplicado sobre a folha e que a utilização de adjuvantes pode reduzir a influência negativa apresentada por essas estruturas foliares.

A molhabilidade da superficie foliar pode ser considerada fator importante no processo de penetração dos herbicidas na planta, sendo fundamental no aumento da eficiência no controle de plantas daninhas. Para ocorrer penetração através da cutícula, a gota de pulverização deve ser retida pela superficie da planta. O uso de adjuvantes nas aplicações de herbicidas pode aumentar o espalhamento, a retenção e a penetração do ingrediente ativo pela superficie foliar, bem como reduzir o período mínimo sem chuva para que haja absorção do produto. O emprego desses aditivos pode promover consideráveis beneficios econômicos e ambientais, devido à possibilidade de redução da dose do ingrediente ativo recomendada (Matuo et al., 1989; Kirkwood, 1993).

O mecanismo de ação dos surfatantes está relacionado com o aumento efetivo da área de contato da gota pulverizada com a superficie foliar, a dissolução ou rompimento de ceras epicuticulares, a prevenção ou retardamento da formação de cristais na gota pulverizada e a promoção da absorção dos compostos pela via estomática (Stock \& Holloway, 1993). O surfatante Silwet L-77 pode proporcionar reduções na tensão superficial da calda de pulverização em aproximadamente 19,5 a 
$22,9 \mathrm{mN} \mathrm{m}^{-1}$, assegurando excelente molhamento da superfície adaxial da folha e permitindo a penetração da calda pela via estomática (Buick et al., 1993).

A atividade biológica de pesticidas aplicados sobre as folhas está relacionada com vários fatores referentes à interação físicoquímica da formulação e a superficie da planta. Dessa maneira, um importante aspecto dessa interação, a qual determina principalmente o caráter inicial e a subseqüente disponibilidade de depósito, é o comportamento da gota de pulverização, como o impacto e a acumulação sobre a superficie foliar, antes da penetração ou evaporação do líquido (Johnstone, 1973).

De acordo com Mendonça (2000), o conhecimento da planta-alvo e a calda de aplicação tornam-se fundamentais para o sucesso da pulverização agrícola, especialmente no caso da utilização de herbicidas. Além das influências intrinsecas às plantas, como disposição das folhas, $\mathrm{pH}$ foliar, ceras epicuticulares, estômatos, tricomas e outras, existem também as influências extrínsecas, como as características fisico-químicas da solução de pulverização, destacando-se a tensão superficial, a área de molhamento, o pH da solução e o tipo de formulação, havendo necessidade de intensificar os estudos referentes a estes fatores. O conhecimento das características botânicas das espécies de plantas daninhas aquáticas é de grande utilidade, especialmente na diferenciação de espécies. Entretanto, estudos morfológicos, principalmente relacionados com a anatomia foliar de plantas aquáticas e correlacionados com a deposição de gotas de pulverização, são bastante escassos no Brasil.

Dessa forma, o objetivo do presente trabalho foi estudar, em três espécies de plantas daninhas aquáticas da família Poaceae, o $\mathrm{pH}$ da superficie foliar e a área de molhamento de gotas de pulverização na superficie foliar (adaxial e abaxial), utilizando soluções com diferentes tensões superficiais.

\section{MATERIAL E MÉTODOS}

As plantas daninhas aquáticas utilizadas no experimento foram Brachiaria mutica, Brachiaria subquadripara e Panicum repens. O experimento foi conduzido no Núcleo de Pesquisas Avançadas em Matologia - NUPAM, do Departamento de Produção Vegetal, pertencente à Faculdade de Ciências Agronômicas de Botucatu/UNESP. As plantas daninhas aquáticas foram obtidas e reproduzidas por meio de suas estruturas de dispersão vegetativa, acondicionadas em pleno sol, em caixas d'água de fibra de vidro de 320 litros, contendo no fundo uma camada de $15 \mathrm{~cm}$ de solo. A instalação do experimento foi realizada em março de 2002, e as plantas apresentaram período de desenvolvimento de quatro meses. Os resultados da análise química do solo utilizado evidenciaram $\mathrm{pH}$ em $\mathrm{CaCl}_{2}$ de 5 , teor de matéria orgânica de $16 \mathrm{~g} \mathrm{dm}^{-3}$, CTC de 75 e $\mathrm{P}$ de $70 \mathrm{mg} \mathrm{dm}^{-3}$, valores de 1,9, 28 e $9 \mathrm{mmol}_{\mathrm{c}} \mathrm{dm}^{-3}$ para $\mathrm{K}$, Ca e $\mathrm{Mg}$, respectivamente, e saturação por bases de 39\%.

As plantas foram avaliadas quando apresentavam seu pleno desenvolvimento (antes do florescimento). Para todas as espécies, foi coletada a terceira folha completamente desenvolvida, contada a partir da primeira folha desenvolvida no sentido do ápice do ramo para a base.

$\mathrm{O} \mathrm{pH}$ foliar foi determinado nas faces adaxial e abaxial da folha de cada espécie, utilizando-se phgâmetro (marca Corning, modelo 314 pH/Temperature Plus) conectado a um microeletrodo (marca Digimed, Modelo DME-CV7). Foi colocada uma gota de $35 \mu \mathrm{L}$ de água destilada entre a superfície foliar e o microeletrodo. Ao se iniciar cada leitura, foi determinado o $\mathrm{pH}$ da água destilada, ou seja, toda leitura iniciou-se do $\mathrm{pH}$ da água destilada, sendo as leituras feitas a cada 10 segundos, considerando-se o resultado final no momento em que o equipamento indicou leitura constante no valor de $\mathrm{pH}$. Para cada espécie de planta daninha aquática foram realizadas oito repetições ou determinações.

No preparo das soluções foi utilizado o herbicida glyphosate $\left(5,0 \% \mathrm{v} \mathrm{v}^{-1}\right.$ do produto comercial Rodeo $480 \mathrm{~g} \mathrm{~L}^{-1}$ e.a.) sem a adição de surfatantes e com a adição dos surfatantes Aterbane BR e Silwet L-77, nas concentrações do produto comercial de $0,5 \% \mathrm{v} \mathrm{v}^{-1}$ e $0,05 \% \mathrm{v} \mathrm{v}^{-1}$, respectivamente.

A tensão superficial das soluções utilizada na determinação da área de molhamento da gota de pulverização foi obtida seguindo a metodologia proposta por Corrêa \& Velini (2002).

Planta Daninha, Viçosa-MG, v. 23, n. 2, p. 295-304, 2005 
Foi usado um equipamento composto por uma base de acrílico, um micromotor, uma seringa de $3 \mathrm{~mL}$ com agulha e um capilar de cromatografia. O micromotor funcionou a uma velocidade constate de 1,03 rpm, gerando gotas de tamanho uniforme na extremidade do capilar. Este equipamento foi posicionado sobre a capela de uma balança de precisão; a gota formada na extremidade do capilar depositavase em um béquer localizado dentro da balança, contendo $40 \mathrm{~mL}$ de óleo vegetal, para evitar a evaporação da gota. A tensão superficial foi determinada através de medições das massas (g) de conjuntos de 50 gotas por repetição, para cada solução utilizada. Foram utilizadas seis repetições por tratamento.

Os valores das tensões superficiais obtidas foram: $72,6 \mathrm{mN} \mathrm{m}^{-1}$, referente à tensão superficial da água destilada (testemunha); $72,1 \mathrm{mN} \mathrm{m}^{-1}$, para a solução com glyphosate aplicado isoladamente; $28,7 \mathrm{mN} \mathrm{m}^{-1}$, para glyphosate + Aterbane BR; $23,3 \mathrm{mN} \mathrm{m}^{-1}$, para glyphosate + Silwet L-77; $37,3 \mathrm{mN} \mathrm{m}^{-1}$, para a solução com o surfatante Aterbane BR aplicado isoladamente; e $22,1 \mathrm{mN} \mathrm{m}^{-1}$, para a solução com o surfatante Silwet L-77 aplicado isoladamente.

Foram determinadas as áreas de molhamento da gota de pulverização nas faces adaxial (superior) e abaxial (inferior) do limbo foliar das espécies estudadas, em oito repetições. Em cada determinação da área de molhamento, as folhas das plantas aquáticas foram fixadas por uma fita dupla adesiva no campo ótico de um fotoestereomicroscópio, sendo em seguida colocada uma gota de $0,5 \mu \mathrm{L}$ da solução dos tratamentos sobre as faces das folhas das espécies.

Para melhor visualização da área de molhamento, foi utilizado o corante Azul Brilhante $\left(0,4 \% \mathrm{v} \mathrm{v}^{-1}\right)$, sendo realizado um estudo preliminar para se determinar a concentração do corante em que não ocorreria interferência na tensão superficial da água destilada (Figura 1). As gotas das soluções dos tratamentos foram colocadas sobre as faces da folha, com auxilio de uma micropipeta, e imediatamente fotografadas através de fotoestereomicroscópio. As mensurações da área de molhamento foram feitas com auxílio de uma mesa digitalizadora acoplada a um computador equipado com o programa de
Sistema de Planimetria (SPLAN), desenvolvido pelo CINAG - UNESP/Botucatu-SP.

Para os dados de $\mathrm{pH}$ foliar nas faces adaxial e abaxial da folha, utilizou-se o delineamento inteiramente casualizado, enquanto para os dados da área de molhamento da gota de pulverização nas faces foliares adaxial e abaxial utilizou-se o fatorial 2x6 (duas faces $\mathrm{x}$ seis tensões superficiais). Todos os dados foram submetidos à análise de variância pelo teste $\mathrm{F}$, sendo as médias comparadas estatisticamente pelo teste " $\mathrm{t}$ " $(\mathrm{p}<0,05)$, determinandose ainda os intervalos de confiança mínimo e máximo (Pimentel-Gomes, 1976).

\section{RESULTADOS E DISCUSSÃO}

Na Tabela 1 estão apresentadas as médias de $\mathrm{pH}$ foliar, os intervalos de confiança mínimo e máximo, valor de $F_{\text {faces }}$, d.m.s. e $C V \%$. Observa-se que o $\mathrm{pH}$ foliar entre as faces adaxial e abaxial foi semelhante para as três espécies estudadas, sendo o valor do $F_{\text {faces }}$ da análise de variância não-significativo, corroborando o fato de não haver diferenças estatísticas de $\mathrm{pH}$ foliar entre as faces.

As médias de $\mathrm{pH}$ foliar variaram entre 5,50 e 6,50, destacando-se Brachiaria mutica, que obteve as maiores médias, com valores em torno de 5,72 e 6,03 para as faces adaxial e abaxial, respectivamente. Todas as espécies apresentaram médias para a face abaxial ligeiramente superiores àquelas da face adaxial da folha. Mendonça (2000), avaliando o pH foliar de plantas daninhas terrestres, observou variação na ordem de 4,0 a 6,0 para a face adaxial da folha; a espécie Commelina benghalensis apresentou o maior valor $(6,0)$, e Cenchrus echinatus, o menor valor $(4,4)$ de $\mathrm{pH}$ foliar.

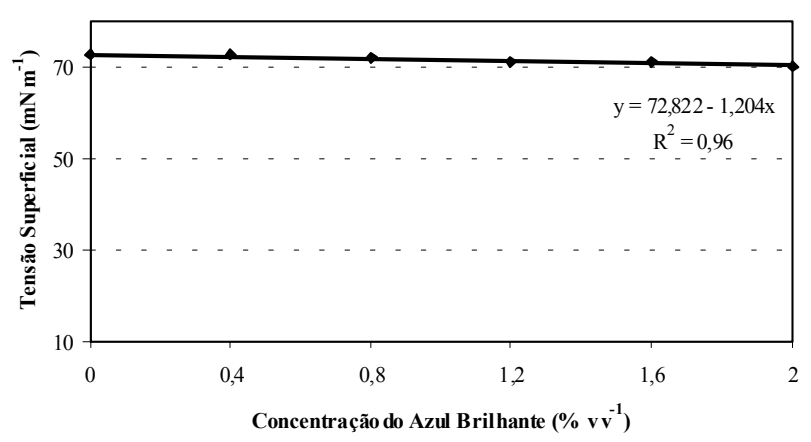

Figura 1 - Curva da tensão superficial do corante Azul Brilhante. Botucatu-SP, 2004. 
Existem na literatura poucas informações referentes à influência do $\mathrm{pH}$ da superficie da folha no processo de absorção dos herbicidas. Contudo, Velini \& Trindade (1992) explicam que o herbicida glyphosate torna-se progressivamente menos apto a atravessar as membranas das células com a elevação do pH; a pH 5, cerca de 79,36 e 20,64\% das moléculas de glyphosate encontram-se na forma de ânions mono e divalentes, respectivamente, enquanto a pH 8 cerca de 0,38 e 99,62\% das moléculas encontram-se na forma de ânions mono e divalentes, respectivamente; dessa forma, com o aumento do $\mathrm{pH}$ de 5 para 8 , o glyphosate torna-se mais ionizado e hidrofilico. A absorção de compostos lipofílicos ocorre de forma mais eficiente e rápida do que a de compostos hidrofilicos.

Assim, esse comportamento pode indicar que espécies que possuem $\mathrm{pH}$ da superficie foliar elevado apresentam, durante o processo de absorção do glyphosate pela folha, dificuldades de absorção pela via lipofilica, devido à mudança das características físico-químicas do produto.

As médias da área de molhamento proporcionada por uma gota de $0,5 \mu \mathrm{L}$ de soluções com diferentes tensões superficiais, nas faces adaxial e abaxial das folhas de diferentes espécies de plantas daninhas aquáticas, estão apresentadas na Tabela 2 .

Tabela 1 - pH foliar das faces adaxial e abaxial das diferentes espécies de plantas daninhas aquáticas, com suas respectivas médias, intervalos de confiança mínimo e máximo, valor de $\mathrm{F}_{\text {faces }}$, d.m.s. e CV\%. Botucatu-SP, 2004

\begin{tabular}{|c|c|c|c|c|c|c|}
\hline Espécie & Média & IC min. & IC máx. & $\mathrm{F}_{\text {faces }}$ & d.m.s. & $\mathrm{CV} \%$ \\
\hline $\begin{array}{c}\text { Brachiaria mutica } \\
\text { Face adaxial } \\
\text { Face abaxial }\end{array}$ & $\begin{array}{l}5,72 \mathrm{a} \\
6,03 \mathrm{a}\end{array}$ & $\begin{array}{l}5,45 \\
5,76\end{array}$ & $\begin{array}{l}5,99 \\
6,30\end{array}$ & $2,97^{\mathrm{ns}}$ & 0,38 & 6,04 \\
\hline $\begin{array}{l}\text { Brachiaria subquadripara } \\
\text { Face adaxial } \\
\text { Face abaxial }\end{array}$ & $\begin{array}{l}5,84 \mathrm{a} \\
5,88 \mathrm{a}\end{array}$ & $\begin{array}{l}5,59 \\
5,62\end{array}$ & $\begin{array}{l}6,14 \\
6,14\end{array}$ & $0,05^{\mathrm{ns}}$ & 0,36 & 5,76 \\
\hline $\begin{array}{r}\text { Panicum repens } \\
\text { Face adaxial } \\
\text { Face abaxial }\end{array}$ & $\begin{array}{l}5,71 \mathrm{a} \\
5,79 \mathrm{a} \\
\end{array}$ & $\begin{array}{l}5,54 \\
5,62 \\
\end{array}$ & $\begin{array}{l}5,89 \\
5,97 \\
\end{array}$ & $0,48^{\mathrm{ns}}$ & 0,25 & 4,01 \\
\hline
\end{tabular}

Médias seguidas pela mesma letra na coluna não diferem estatisticamente entre si pelo teste $\mathrm{t}(\mathrm{p}<0,05) ;{ }^{\text {ns }}$ não-significativo.

Tabela 2 - Área de molhamento $\left(\mathrm{mm}^{2}\right)$ proporcionada por uma gota de $0,5 \mu \mathrm{L}$ de soluções com diferentes tensões superficiais, nas faces adaxial e abaxial das folhas de diferentes espécies de plantas daninhas aquáticas. Botucatu-SP, 2004

\begin{tabular}{|c|c|c|c|c|c|c|c|}
\hline \multirow{3}{*}{ Espécie } & \multicolumn{6}{|c|}{ Tensão Superficial da gota $\left(\mathrm{mN} \mathrm{m}^{-1}\right)$} & \multirow{3}{*}{ Média } \\
\hline & 72,6 & 72,1 & 37,3 & 28,7 & 22,1 & 23,3 & \\
\hline & $\begin{array}{c}\text { Água } \\
\text { destilada }\end{array}$ & glyphosate* & Aterbane BR & $\begin{array}{l}\text { glyphosate }+ \\
\text { Aterbane BR }\end{array}$ & Silwet L-77 & $\begin{array}{l}\text { glyphosate + } \\
\text { Silwet L-77 }\end{array}$ & \\
\hline \multicolumn{8}{|l|}{ Brachiaria mutica } \\
\hline Face adaxial & $0,83 \mathrm{aC}$ & $0,92 \mathrm{aC}$ & $1,77 \mathrm{aC}$ & $5,13 \mathrm{aB}$ & $10,30 \mathrm{aA}$ & $6,20 \mathrm{aB}$ & $4,19 \mathrm{a}$ \\
\hline Face abaxial & $1,05 \mathrm{aE}$ & $1,27 \mathrm{aDE}$ & $2,62 \mathrm{aCD}$ & $3,81 \mathrm{aC}$ & $8,60 \mathrm{bA}$ & $5,41 \mathrm{aB}$ & $3,79 \mathrm{a}$ \\
\hline Médias & $0,94 \mathrm{E}$ & $1,09 \mathrm{E}$ & $2,19 \mathrm{D}$ & $4,47 \mathrm{C}$ & $9,45 \mathrm{~A}$ & $5,81 \mathrm{~B}$ & \\
\hline \multicolumn{8}{|l|}{ Brachiaria subquadripara } \\
\hline Face adaxial & $0,75 \mathrm{aC}$ & $0,89 \mathrm{aC}$ & $1,55 \mathrm{bC}$ & $6,44 \mathrm{aB}$ & $10,94 \mathrm{aA}$ & $7,77 \mathrm{bB}$ & $4,72 \mathrm{~b}$ \\
\hline Face abaxial & $1,86 \mathrm{aC}$ & $2,09 \mathrm{aC}$ & $4,45 \mathrm{aB}$ & $4,36 \mathrm{bB}$ & $10,28 \mathrm{aA}$ & $10,59 \mathrm{aA}$ & $5,60 \mathrm{a}$ \\
\hline Médias & $1,31 \mathrm{E}$ & $1,49 \mathrm{E}$ & $3,00 \mathrm{D}$ & $5,40 \mathrm{C}$ & $10,61 \mathrm{~A}$ & $9,18 \mathrm{~B}$ & \\
\hline \multicolumn{8}{|l|}{ Panicum repens } \\
\hline Face adaxial & $0,72 \mathrm{aC}$ & $0,70 \mathrm{aBC}$ & $1,37 \mathrm{aBC}$ & $4,86 \mathrm{aA}$ & $5,66 \mathrm{bA}$ & $1,63 \mathrm{bB}$ & $2,49 \mathrm{~b}$ \\
\hline Face abaxial & $0,69 \mathrm{aD}$ & $0,76 \mathrm{aD}$ & $2,12 \mathrm{aC}$ & $5,57 \mathrm{aB}$ & $10,35 \mathrm{aA}$ & $2,59 \mathrm{aC}$ & $3,68 \mathrm{a}$ \\
\hline Médias & $0,70 \mathrm{D}$ & $0,73 \mathrm{D}$ & $1,74 \mathrm{C}$ & $5,22 \mathrm{~B}$ & $8,00 \mathrm{~A}$ & $2,11 \mathrm{C}$ & \\
\hline
\end{tabular}

Médias seguidas de mesma letra, minúsculas na coluna e maiúsculas na linha, não diferem estatisticamente entre si pelo teste $\mathrm{t}(\mathrm{p}<0,05)$.

* Produto comercial - Rodeo $480 \mathrm{~g} \mathrm{~L}^{-1}$ e. a. 
As tensões superficiais das gotas apresentadas pelas soluções de glyphosate isoladamente $\left(5,0 \% \mathrm{v} \mathrm{v}^{-1}\right)$, glyphosate + Aterbane BR $\left(5,0 \%+0,5 \% \mathrm{v} \mathrm{v}^{-1}\right)$ e glyphosate + Silwet L-77 $\left(5,0 \%+0,05 \% \mathrm{v} \mathrm{v}^{-1}\right)$, além das soluções com os adjuvantes isolados, Aterbane BR $\left(0,5 \% \mathrm{v} \mathrm{v}^{-1}\right)$ e Silwet L-77 $\left(0,05 \% \mathrm{v} \mathrm{v}^{-1}\right)$, foram, respectivamente, de $72,1-28,7-23,3-37,3$ e $22,1 \mathrm{mN} \mathrm{m}^{-1} 0,5 \mu \mathrm{L}^{-1}$. Esses dados são semelhantes aos obtidos por Costa (1997) para os mesmos produtos e as mesmas concentrações.

Os dados da tensão superficial da gota de pulverização das soluções de glyphosate em mistura com os adjuvantes Aterbane BR e Silwet L-77 estiveram abaixo da tensão superficial citada por Greene \& Bucovac (1974), que induziria a penetração das soluções pela via estomática $\left(32 \mathrm{mN} \mathrm{m}^{-1}\right)$.

A tensão superficial dos adjuvantes Aterbane BR $\left(0,5 \% \mathrm{v} \mathrm{v}^{-1}\right)$ e Silwet L-77 $\left(0,05 \% \mathrm{v} \mathrm{v}^{-1}\right)$ em água destilada foi superior à encontrada por Mendonça (2000), que, trabalhando com concentrações menores dos adjuvantes Aterbane BR $\left(0,03 \% \mathrm{v} \mathrm{v}^{-1}\right)$ e Silwet L-77 $\left(0,02 \% \mathrm{v} \mathrm{v}^{-1}\right)$, obteve valores de tensão superficial na ordem de 33,8 e $20,8 \mathrm{mN} \mathrm{m}^{-1}$, respectivamente. Montório (2001) verificou que os adjuvantes Aterbane BR e Silwet L-77 apresentaram reduções da tensão superficial da água e coeficiente de eficácia em torno de 32,68 - 19,08 $\mathrm{mN} \mathrm{m}^{-1}$ e 46,38 - 143,43, respectivamente.

Embora não tenha sido constatada diferença estatística na área de molhamento entre as faces adaxial e abaxial dos tratamentos, exceto para o Silwet L-77, maiores médias foram verificadas para as soluções de glyphosate + Aterbane BR, glyphosate + Silwet L-77 e Silwet L-77, com valores na ordem de $5,13-3,81,6,20-5,41$ e $10,30-8,60 \mathrm{~mm}^{2}$ $0,5 \mu \mathrm{L}^{-1}$ de área foliar molhada, respectivamente. Nota-se ainda, na Tabela 2, que na face adaxial das folhas de Brachiaria mutica os tratamentos glyphosate e Aterbane BR não diferiram estatisticamente da água destilada, destacando-se o tratamento Silwet L-77, com $10,3 \mathrm{~mm}^{2} 0,5 \mu \mathrm{L}^{-1}$ de área foliar molhada.

$\mathrm{Na}$ Figura 2 pode-se observar que as soluções de água destilada, glyphosate e Aterbane BR apresentaram maiores médias de área molhada na face abaxial em relação à adaxial, ao passo que as soluções de glyphosate + Aterbane BR, glyphosate + Silwet L-77 e Silwet L-77 mostraram maiores médias de área molhada na face adaxial em relação à abaxial, com valores de $5,13-3,81,6,20$ - 5,41 e $10,30-8,60 \mathrm{~mm}^{2} 0,5 \mu \mathrm{L}^{-1}$, respectivamente. $\mathrm{Na}$ face abaxial da folha de Brachiaria subquadripara foram observados valores de

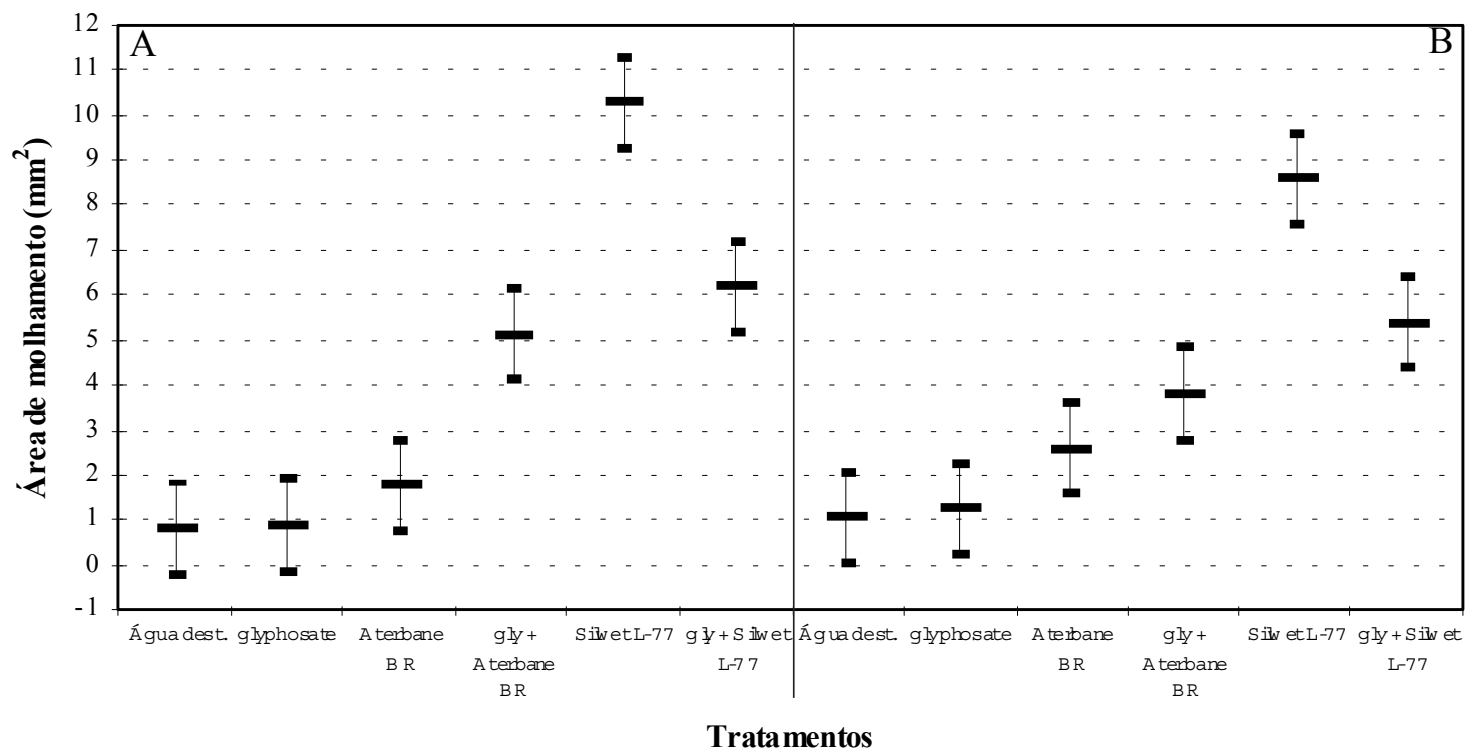

Figura 2 - Área de molhamento de diferentes soluções, proporcionada por uma gota de $0,5 \mu \mathrm{L}$ depositada sobre as faces adaxial (A) e abaxial (B) da folha de Brachiaria mutica (intervalos de confiança mínimo e máximo). Botucatu-SP, 2004. 
área de molhamento mais elevados em comparação aos da face adaxial para as soluções de água destilada, glyphosate, Aterbane BR e glyphosate + Silwet L-77 (Tabela 2 e Figura 3). Entretanto, comportamento inverso foi observado para as soluções de glyphosate + Aterbane BR e Silwet L-77.

As soluções de Aterbane BR, glyphosate + Aterbane BR e glyphosate + Silwet L-77 demonstraram diferenças estatísticas para face dentro de soluções para a espécie Brachiaria subquadripara, porém as soluções de glyphosate + Silwet L-77 e Silwet L-77 destacaram-se dos demais tratamentos, exibindo os maiores valores de área de molhamento para ambas as faces da folha (Tabela 2 e Figura 3).

Os tratamentos de glyphosate em mistura com os adjuvantes Aterbane BR e Silwet L-77 podem proporcionar controle eficiente - próximo de 100\%, - para as espécies Brachiaria mutica e Brachiaria subquadripara, como comprovam os experimentos realizados por Carbonari et al. (2003), que, avaliando o controle dessas gramíneas utilizando os tratamentos glyphosate + Aterbane BR e glyphosate + Silwet L-77 nas concentrações de 4,5 + 0,5\% $\mathrm{v} \mathrm{v}^{-1}$ e $4,5+0,1 \% \mathrm{v} \mathrm{v}^{-1}$, respectivamente, observaram notas de controle superiores a $98 \%$ após 67 dias da aplicação.

Para a espécie Panicum repens, todos os tratamentos avaliados, com exceção da água destilada, demonstraram maior área de molhamento da gota de pulverização na face abaxial em relação à face adaxial da folha. Contudo, apenas as soluções de glyphosate + Silwet L-77 e Silwet L-77 apresentaram diferenças significativas entre as faces, dentro de cada tratamento (Tabela 2 e Figura 4). A solução de Silwet L-77 proporcionou maior espalhamento da gota de pulverização nas faces adaxial e abaxial da folha de Panicum repens, em comparação com os demais tratamentos avaliados. No entanto, a combinação do glyphosate com o adjuvante Aterbane BR mostrou-se mais eficiente no aumento da área de molhamento da gota em relação à combinação do glyphosate com adjuvante Silwet L-77, para ambas as faces da folha, diferindo estatisticamente.

Nas três espécies de gramíneas, foi observado efeito positivo da adição dos adjuvantes Aterbane BR e Silwet L-77 na solução de glyphosate, uma vez que houve dificuldades no momento da deposição da gota, principalmente na face adaxial da folha dessas espécies, provocada pelo efeito de repelência da gota de pulverização das soluções de água destilada e glyphosate sem adjuvante.

Hess \& Falk (1990) e Mendonça (2000) explicam que maiores depósitos de ceras epicuticulares na superficie adaxial da folha podem reduzir o espalhamento da gota de pulverização nesta superfície. Mendonça (2000) observou nas gramíneas Brachiaria decumbens, Brachiaria plantaginea e Panicum maximum maiores áreas de molhamento nas

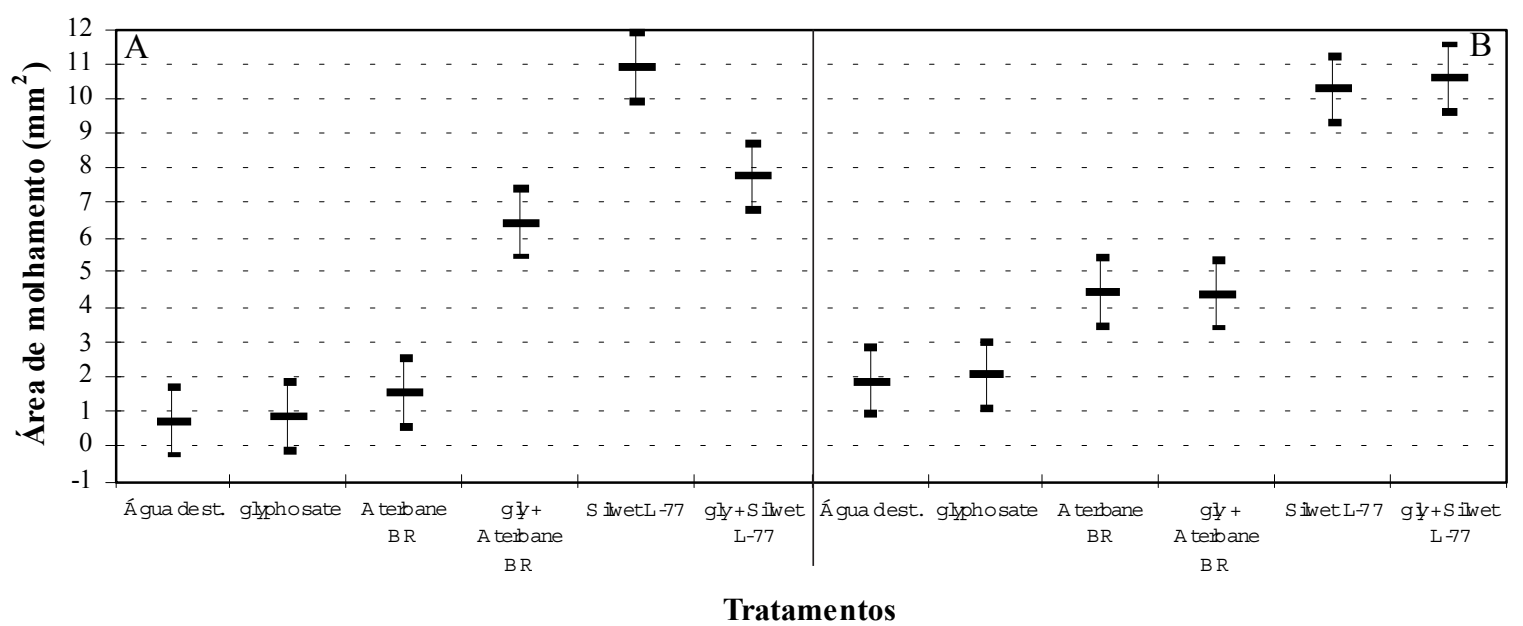

Figura 3 - Área de molhamento de diferentes soluções, proporcionada por uma gota de $0,5 \mu \mathrm{L}$ depositada sobre as faces adaxial (A) e abaxial (B) da folha de Brachiaria subquadripara (intervalos de confiança mínimo e máximo). Botucatu-SP, 2004. 


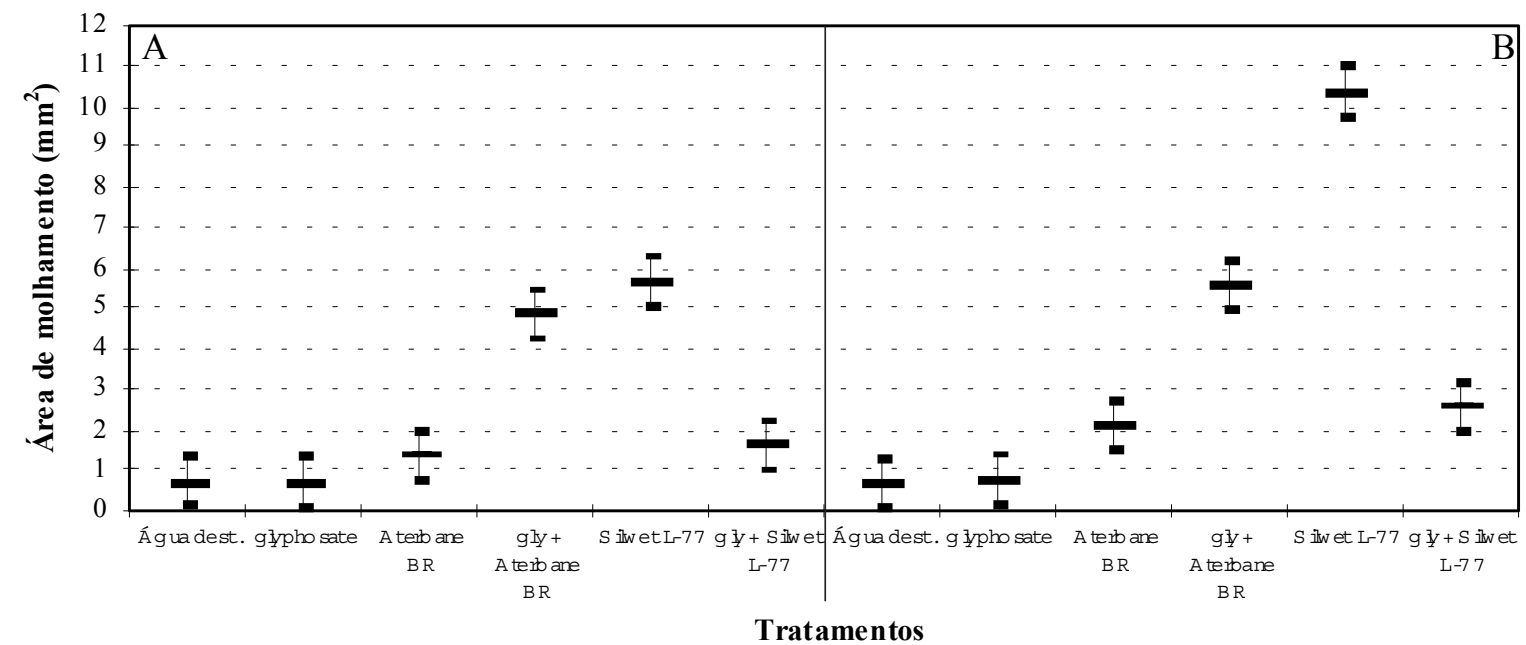

Figura 4 - Área de molhamento de diferentes soluções, proporcionada por uma gota de $0,5 \mu \mathrm{L}$ depositada sobre as faces adaxial (A) e abaxial (B) da folha de Panicum repens (intervalos de confiança mínimo e máximo). Botucatu-SP, 2004.

faces abaxiais da folha, proporcionada pelos adjuvantes Aterbane BR e Silwet L-77 em água destilada, o que é explicado pelos menores depósitos de ceras epicuticulares, evidenciados pelos estudos ultra-estruturais da superficie foliar realizados com a técnica de microscopia eletrônica de varredura.

A melhoria provocada pelos adjuvantes no espalhamento da gota de pulverização nas superficies foliares é atribuída à capacidade de redução da tensão superficial da solução, aumentando a área de contato da gota com a epiderme da folha. A adição de adjuvantes à calda de pulverização nem sempre promove o efeito esperado, visto que as características da superficie foliar exercem grande influência na deposição da gota pulverizada. Em alguns casos, os adjuvantes podem exercer efeito antagônico ao processo de absorção do herbicida pela planta (Field \& Bishop, 1988). Dessa maneira, a avaliação do desempenho dos adjuvantes sob a influência dos compostos constituintes dos herbicidas, bem como da superficie da folha, pode definir o potencial de uso desses produtos em aplicação em pósemergência para o controle de determinada espécie de planta daninha, tanto de ambiente terrestre como de aquático. Efeitos antagônicos e sinérgicos entre os produtos glyphosate+ Silwet L-77 e glyphosate+Aterbane BR, respectivamente, foram observados por Mendonça et al. (1999) em estudos da área de molhamento de soluções de glyphosate sobre folhas de tiririca (Cyperus rotundus).
$\mathrm{Na}$ Figura 5 estão representados os valores dos indices de aumento da área de molhamento da gota de pulverização de soluções com diferentes tensões superficiais, em relação à área de molhamento da gota de água destilada, nas faces adaxial e abaxial da folha das plantas daninhas aquáticas estudadas.

Observa-se que a redução da tensão superficial da gota de pulverização, proporcionada pelos adjuvantes Aterbane BR e Silwet L-77 em mistura com o glyphosate, influenciou positivamente o aumento da área de molhamento nas superficies foliares de todas as espécies de plantas daninhas aquáticas estudadas.

Pode-se observar o aumento no espalhamento da gota de pulverização nas faces das folhas das plantas daninhas aquáticas, promovido pelo adjuvante Aterbane BR em mistura com o glyphosate quando em comparação com o Aterbane BR isolado, revelando um efeito sinérgico entre os produtos (glyphosate + Aterbane BR). Entretanto, com exceção da face abaxial de Brachiaria subquadripara (Tabela 2), o adjuvante Silwet L-77 em mistura com o glyphosate promoveu redução do espalhamento da gota de pulverização nas faces das folhas nas demais espécies de plantas daninhas aquáticas, quando comparado com o tratamento de Silwet L-77 isolado, evidenciando um efeito antagônico entre os produtos glyphosate + Silwet L-77. 


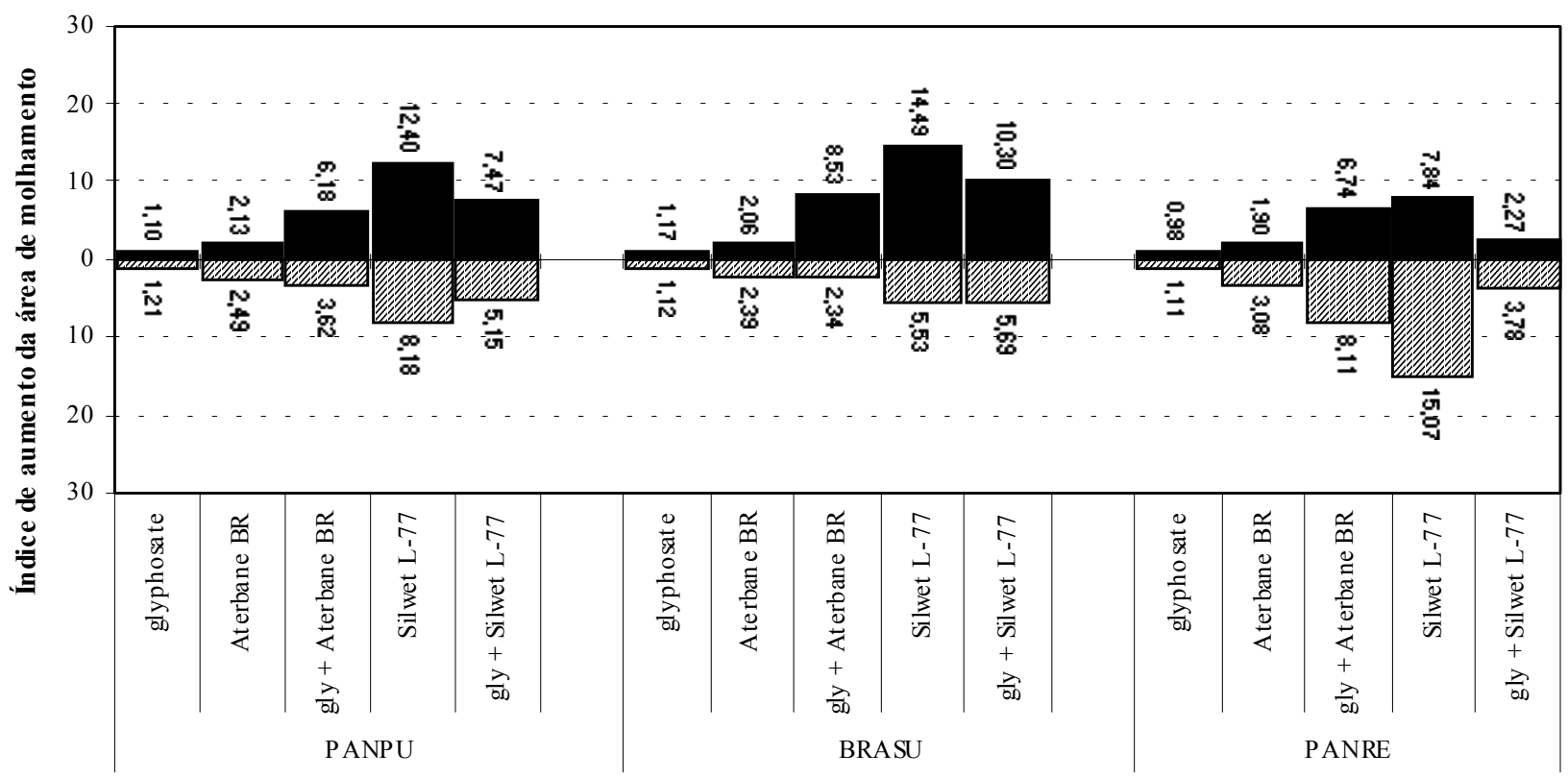

Espécies X Tratamentos

Face adaxial 圆 Face abaxial

Figura 5 - Índice de aumento da área de molhamento da gota $(0,5 \mu \mathrm{L})$ de soluções com diferentes tensões superficiais em relação à área de molhamento da gota de água destilada (testemunha), nas faces adaxial e abaxial da folha de plantas daninhas aquáticas. PANPU - Brachiaria mutica, BRASU - Brachiaria subquadripara, PANRE - Panicum repens. Botucatu-SP, 2004.

Costa (1997) afirma que a avaliação do desempenho dos adjuvantes em soluções sem a adição de herbicidas tem pouca utilidade prática, uma vez que a presença do herbicida pode condicionar valores de tensão superficial diferentes daqueles verificados na sua ausência.

Com base nos resultados obtidos, pode-se constatar que a área de molhamento proporcionada por uma gota de pulverização depositada nas faces foliares adaxial e abaxial das plantas daninhas aquáticas estudadas foi influenciada positivamente, visto que as tensões superficiais da gota de pulverização das soluções de glyphosate em mistura com os adjuvantes Aterbane BR e Silwet L-77 estiveram abaixo da tensão superficial que induziria a penetração das soluções pela via estomática $\left(32 \mathrm{mN} \mathrm{m}^{-1}\right)$. Contudo, deve-se ressaltar a importância da realização de mais estudos referentes à influência do $\mathrm{pH}$ da superficie da folha no processo de absorção dos herbicidas, pelo fato de existirem poucas informações na literatura.

\section{LITERATURA CITADA}

AMARANTE Jr., O. P. et al. Glifosato: propriedades, toxicidade, usos e legislação. Química Nova, v. 25, n. 4, p. 589-593, 2002.

ANTUNIASSI, U. R.; VELINI, E. D.; MARTINS, D. Remoção mecânica de plantas aquáticas: análise econômica e operacional. Planta Daninha, v. 20, p. 35-43, 2002. (Edição Especial)

BUICK, R. D.; BUCHAN, G. D.; FIELD, R. J. The role of surface tension of spreading droplets in absorption of a herbicide formulation via leaf stomata. Pest. Sci., v. 38, p. 227-235, 1993.

CARBONARI, C. A.; MARTINS, D.; TERRA, M. A. Controle de Brachiaria subquadripara e Brachiaria mutica através de diferentes herbicidas aplicados em pósemergência. Planta Daninha, v. 21, p. 79-84, 2003. (Edição especial)

CARDOSO, L. R. Controle químico de diferentes acessos de aguapé (Eichhornia crassipes). Caracterização através de eletroforese (RAPD). 2000. 93 f. Dissertação (Mestrado em Ciências Agronômicas) - Universidade Estadual Paulista, Botucatu, 2000.

Planta Daninha, Viçosa-MG, v. 23, n. 2, p. 295-304, 2005 
CARDOSO, L. R. et al. Variabilidade genética de acessos de aguapé coletados no Estado de São Paulo. Planta Daninha, v. 20, p. 1-6, 2002. (Edição Especial)

CARDOSO, L. R.; MARTINS, D.; TERRA, M. A. Sensibilidade a herbicidas de acessos de aguapé coletados em reservatórios do Estado de São Paulo. Planta Daninha, v. 21, p. 61-67, 2003. (Edição especial)

CORRÊA, T. M.; VELINI, E. D. Desenvolvimento de equipamento para medição da tensão superficial estática de soluções. In: CONGRESSO BRASILEIRO DA CIÊNCIA DAS PLANTAS DANINHAS, 23., 2002, Gramado-RS. Resumos... Gramado: Sociedade Brasileira da Ciência das Plantas Daninhas, 2002. p. 686.

COSTA, E. A. D. Efeitos de surfatantes sobre a tensão superficial de soluções de Rodeo. 1997. $73 \mathrm{f}$.

Dissertação (Mestrado em Ciências Agronômicas/Proteção de Plantas) - Universidade Estadual de Paulista, Botucatu, 1997.

ESTEVES, F. A. Fundamentos de limnologia. 2.ed. Rio de Janeiro: Interciência, 1998. 602 p.

FIELD, R. J.; BISHOP, N. G. Promotion of stomatal infiltration of glyphosate by an organosilicone surfactant reduces the critical rainfall period. Pesticide Sci., v. 24, p. 55-62, 1988.

GREENE, D. W.; BUKOVAC, M. J. Stomatal penetration: effect of surfatants and role in foliar absorption. Am. J. Bot., v. 61, n. 1, p. 100-106, 1974.

HESS, F. D.; FALK, R. H. Herbicide deposition on leaf surfaces. Weed Sci., v. 38, p. 280-288, 1990.

JOHNSTONE, D. R. Spreading and retention of agricultural sprays on foliage. In: DEKKER, M. Pesticide formulations. New York: Edição do autor, 1973. 481 p.

KIRKWOOD, R. C. Use and mode of action of adjuvants for herbicides: a review of some current work. Pest. Sci., v. 38 , p. 93-102,1993.
MATUO, T.; NAKAMURA, S. H.; ALMEIDA, A. Efeitos de alguns adjuvantes da pulverização nas propriedades físicas do líquido. Summa Phytopathol., v. 15, p. 163-173, 1989.

MARTINS, D. et al. Controle químico de plantas daninhas aquáticas em condições controladas-caixas d'água. Planta Daninha, v. 17, n. 2, p. 289-296, 1999.

MENDONÇA, C. G. et al. Avaliação da tensão superficial e área de molhamento de soluções de glyphosate com surfatantes em folhas de tiririca. Planta Daninha, v. 17, n. 3, p. 355-365, 1999.

MENDONÇA, C. G. Algumas características da superfície foliar de diversas plantas daninhas monocotiledôneas. 2000. 89 f. Dissertação (Mestrado em Agronomia) - Universidade Estadual Paulista "Júlio de Mesquita Filho", Botucatu, 2000.

MONTÓRIO, G. A. Eficiência dos surfatantes de uso agrícola na redução da tensão superficial. 2001. $72 \mathrm{f}$. Tese (Doutorado em Ciências Agronômicas/Proteção de Plantas) - Universidade Estadual Paulista, Botucatu, 2001.

PIMENTEL-GOMES, F. Curso de estatística experimental. 6.ed. Piracicaba: Gráfica Binetti, 1976. $430 \mathrm{p}$.

RODRIGUES, B. N.; ALMEIDA, F. S. Guia de herbicidas. 4.ed. Londrina: Edição dos autores, 1998. 648 p.

STOCK, D.; HOLLOWAY, P. J. Possible mechanisms for surfactant-induced foliar uptake of agrochemicals. Pest. Sci., v. 38, p. 165-177, 1993.

TANAKA, R. H. et al. Ocorrência de plantas aquáticas nos reservatórios da Companhia Energética de São Paulo. Planta Daninha, v. 20, p. 101-111, 2002. (Edição especial)

VELINI, E. D.; TRINDADE, M. L. B. Comportamento de herbicidas na planta. Épocas de aplicação de herbicidas. In: SIMPÓSIO NACIONAL SOBRE MANEJO INTEGRADO DE PLANTAS DANINHAS EM HORTALIÇAS, 1992, Botucatu/SP. Anais... Botucatu: UNESP, 1992. p. 65-86. 